archives

of thermodynamics

Vol. 36(2015), No. 3, 25-48

DOI: $10.1515 /$ aoter-2015-0020

\title{
Exergy analysis of the Szewalski cycle with a waste heat recovery system
}

\author{
TOMASZ KOWALCZYK ${ }^{a, b 1}$ \\ PAWEŁ ZIÓŁKOWSKI ${ }^{a, b}$ \\ JANUSZ BADUR ${ }^{a}$
}

a Energy Conversion Department, The Szewalski Institute of Fluid-Flow Machinery of the Polish Academy of Sciences, Fiszera 14, 80-231 Gdańsk, Poland

${ }^{b}$ Gdansk University of Technology, Conjoint Doctoral School at the Faculty of Mechanical Engineering, Gabriela Narutowicza 11/12 st., 80-233 Gdańsk, Poland

\begin{abstract}
The conversion of a waste heat energy to electricity is now becoming one of the key points to improve the energy efficiency in a process engineering. However, large losses of a low-temperature thermal energy are also present in power engineering. One of such sources of waste heat in power plants are exhaust gases at the outlet of boilers. Through usage of a waste heat regeneration system it is possible to attain a heat rate of approximately $200 \mathrm{MW}_{t h}$, under about $90^{\circ} \mathrm{C}$, for a supercritical power block of $900 \mathrm{MW}_{e l}$ fuelled by a lignite. In the article, we propose to use the waste heat to improve thermal efficiency of the Szewalski binary vapour cycle. The Szewalski binary vapour cycle provides steam as the working fluid in a high temperature part of the cycle, while another fluid - organic working fluid - as the working substance substituting conventional steam over the temperature range represented by the low pressure steam expansion. In order to define in detail the efficiency of energy conversion at various stages of the proposed cycle the exergy analysis was performed. The steam cycle for reference conditions, the Szewalski binary vapour cycle as well as the Szewalski hierarchic vapour cycle cooperating with a system of waste heat recovery have been comprised.
\end{abstract}

\footnotetext{
${ }^{1}$ Corresponding Author. E-mail: tkowalczyk@imp.gda.pl
} 
Keywords: Szewalski cycle; Binary vapour cycle; Exergy analysis; Waste heat

\section{Nomenclature}

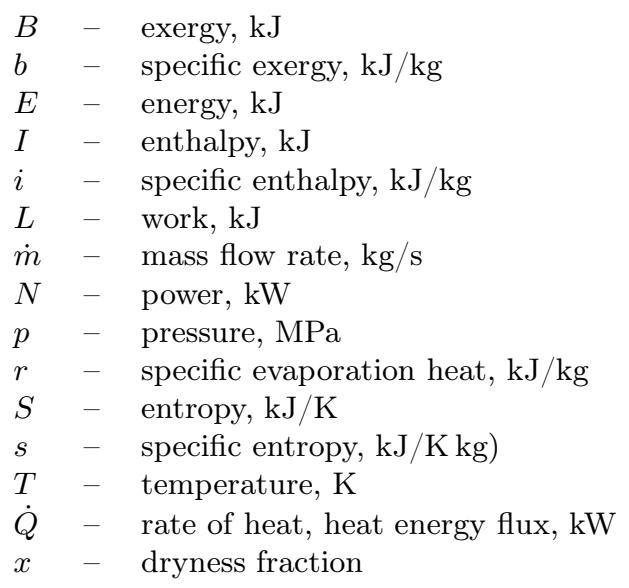

\section{Greek symbols}

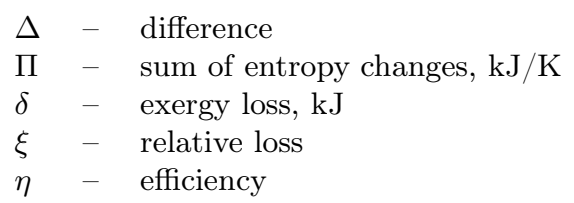

\section{Subscripts}

\begin{tabular}{|c|c|c|}
\hline$B$ & - & boiler, exergy \\
\hline$C$ & - & Carnot, condenser \\
\hline$C-R$ & - & Clausius-Rankine cycle \\
\hline ch & - & chemical \\
\hline$D$ & - & driving exergy \\
\hline Fuel & - & fuel \\
\hline G & - & electric generator \\
\hline$H E$ & - & heat exchanger \\
\hline$i$ & - & number of device, cycle \\
\hline int & - & internal \\
\hline$k$ & - & kinetic \\
\hline$m$ & - & mechanical \\
\hline $\max$ & - & maximum \\
\hline
\end{tabular}




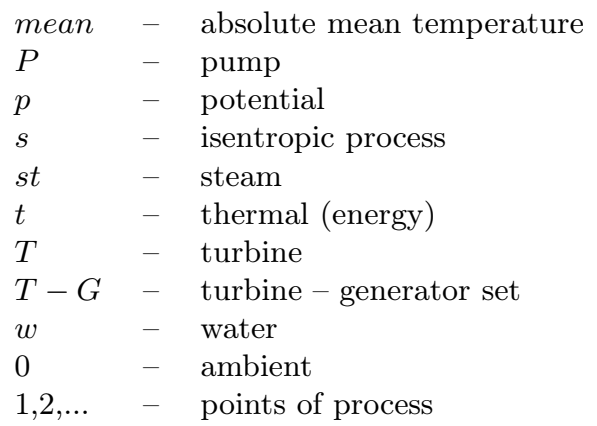

\section{Introduction}

In the 1960s, Robert Szewalski introduced a binary vapour cycle consisting of a supercritical steam cycle and an organic Rankine cycle (ORC) coupled in a hierarchical energy system. The purpose of this idea was to facilitate the design of power units producing an order of few gigawatts of power. However, the importance of the binary cycle increases in the low-temperature range - for example in waste heat recovery systems. The Szewalski binary vapour cycle $[1,2]$ uses steam as a working fluid in the high-temperature part of the cycle; another fluid - an organic working fluid with a low specific volume - is used as a working substance in the conventional steam over a range of temperature covered by low-pressure (LP) steam expansion.

The most recent analysis of a thermodynamic and operational parameters of the Szewalski binary vapour cycle was performed by Kowalczyk et al. [3], who presented the energy and exergy analysis of the Szewalski binary vapour cycle based on a model of a supercritical steam power plant. The energy analysis was used to conduct a preliminary optimization of the cycle; exergy losses analysis (second law efficiency) is employed to perform a study of heat-transfer processes, which are essential for hierarchical cycles. They obtained the reduction of the 'cold end' of the turbine which is desirable from economic and technical standpoints [3]. Another analysis of thermodynamic and operational parameters of the Szewalski binary vapour cycle was performed by Ziółkowski et al. [4]. This analysis was carried out using accessible numerical computational flow mechanics (CFM) codes via stepby-step modelling of separate elements of the cycle. In the Szewalski binary vapour cycle, there were considered four potential working fluids (propane, isobutene, ethanol and ammonia) to obtain the highest output and a first law efficiency of the cycle. One of the concepts presented in Ziółkowski et al. paper is the cooperation of Szewalski hierarchic vapour cycle with a system 
of waste heat recovery from exhaust gases. Four working fluids in the low temperature part of binary cycle such as ammonia, propane, isobutene and ethanol had been investigated. Moreover, the Szewalski cycle was a good resolution for proper using heat rate received from the exhaust gases heat regeneration system [5].

Another supercritical steam cycle that employed an ORC cycle has been analysed in the literature [6,7]. The objective of these studies was to analyse the thermodynamic and operational parameters of a supercritical power plant given the reference conditions. This research was also focused on an introduction of a hybrid system incorporating an ORC. In the ORC, the upper heat source is a stream of hot water from a system of heat recovery system with a temperature of $90^{\circ} \mathrm{C}$, which is additionally aided by heat from steam bleeds of the LP steam turbine. Ziółkowski and Mikielewicz [6] conducted a thermodynamic analysis of the supercritical power plant with and without incorporation of the ORC using CFM numerical codes. Four fluids (propane, isobutane, pentane and ethanol) [6], as well as six working fluids (propane, isobutane, pentane, ethanol, R236ea and R245fa) were investigated [7]. In the course of the calculations, it was determined that the unit power increased. Moreover that the first law efficiency was established for the reference case and the case with the ORC.

One of the concepts presented in Mikielewicz et al. works [8,9] assumed design of a binary cycle for increase the efficiency, using low-boiling point fluids in the installation cooperating with the supercritical power plant. As a result of such cooperation, the ORC can utilize the available waste heat, by concept of heat supply to the ORC installation with usage of waste heat flux from flue gases, heat flux from a $\mathrm{CO}_{2}$ capture installation and heat flux from a LP extraction of steam. This issue is discussed in works [8,9]. Eukowicz and Kochaniewicz [10] have described a technology that uses the waste heat flux obtained from exhaust gases. This paper also presented an analysis of the feasibility and potential for using waste heat obtained from exhaust gases to feed ORCs.

A general exergy analysis of hierarchical cycles was presented by Bartnik [11], who found that in a general case, the number of circulating media in hierarchic cycles can be arbitrarily large. An increase of the number of media with various temperatures of the operating range makes it possible to apply in a system higher range of the temperature increase between the upper and lower heat sources (environment). Thereby, exergy losses in the system are reduced and the production of electricity increases. The disad- 
vantage of such a solution for increase the investment required to start the system. However, the loss of exergy stream in hierarchical $j$-cycle system comes as a consequence of mere increase of entropy streams of external heat source which are in contact with it (in practice we usually have to do with two sources) [11].

Exergy analysis is an important tool for the optimization of complex thermodynamic processes because energy balance alone does not include entropy generation and therefore energy quality degradation. For technical and economic reasons, the quality of energy is closely related to investment and maintenance costs $[12,13]$. It should be noted that the first law analysis is not only incomplete but also misleading because it distorts the real resource consumption quantifiers and overestimates low-exergy (high-entropy) fluxes [14]. A good example of an exergy analysis of a power cycle [15], in which Cenusa et al. have presented an original and rapid method for heat recovery steam generator (HRSG) exergetic optimization. The main aim of the analysis was to maximize exergy transfer to the water/steam cycle. The proposed approach fixes the pinch point and the economics by imposing the total heat transfer area of the HRSG. In another study [16], Feidt has proposed reconsidering direct and inverse configurations of Carnot machines, and he presented two examples. The first example is concerned with a 'thermofrigo-pump' in which the two utilities are hot and cold thermal exergies due to the difference in the temperature level compared with the ambient temperature. The second example is relative to a combined heat and power (CHP) system [16].

It should be noted that due to environmental-impact considerations and energy-conversion efficiency, the renewal and development of heat pumps and CHP systems has been increasing from large- to microscale systems $(\mu \mathrm{CHP})$ for industrial, building applications and even photovoltaic/thermal $(\mathrm{PV} / \mathrm{T})$ configurations or fuel cell CHP systems [17-28]. Energy and exergy analyses were conducted by many authors, for example: 1) a combined heat and power system by Feidt and Costea [17]; 2) a novel hybrid solar heating, cooling and power generation system for remote areas was analysed by Zhai et al. [18]; 3) a two-phase ejector in compression refrigeration system was developed by Dudar et al. [19]; 4) the proton exchange membrane fuel cell and solid oxide fuel cell-based $\mu \mathrm{CHP}$ systems was compared by Barelli et al. [20]. Additionally exergy analyses of poly-generation systems for sustainable building applications were conducted by Bingöl et al. [21]. Nieminen and Dincer [22] compared gasoline and hydrogen fuelled internal combus- 
tion engines using exergy analyses. A review of exergo-economic analysis and optimization of combined heat and power production was performed by Abusoglu and Kanoglu [23].

According to Szargut's proposal [24], exergy is an adequate measure of the quality of natural resources. a complete example concerning the analysis of thermo-ecological cost has been presented in [25]. These authors focused on an ecological analysis of coal injection as auxiliary fuel to the Tuyere zone of a blast furnace. Connections with coal mines, coke-oven batteries and power plants have been considered. The summary of Szargut's investigations on this subject has been presented in [24]. In a recent work, Ziębik and Gładysz $[26,27]$ presented an algorithm for calculating the thermo-ecological costs of an integrated oxy-fuel combustion power plant based on an 'inputoutput' model of direct energy and materials consumption and also on the application of an 'input-output' approach for the construction of a mathematical model of the thermo-ecological costs of such a power plant. In order to construct this model, the authors assumed that interconnections between the analysed integrated oxy-fuel combustion power plant and domestic economy were rather weak, which permitted them to establish indices of thermo-ecological costs concerning fuels, raw materials and semiproducts on the basis of apriori knowledge [26]. However, the thermo-ecological optimization of a solar collector has been also established [28].

The main aim of the present paper is exergy analysis of Szewalski hierarchic vapour cycle cooperating with a system of waste heat recovery from exhaust gases. The paper presents a comparative analysis of 900 MWe supercritical power plant, the Szewalski binary vapour cycle and the Szewalski hierarchic vapour cycle cooperating with a waste heat recovery system from exhaust gases, using second law efficiency for the reference case without ORC and with considerations of the latter.

\section{The analysed cycles}

\subsection{The reference model}

Performed analysis of the exergy losses in a binary vapour cycle is based on a CFM model of a supercritical steam power plant, named as a reference model. The thermodynamic cycle consists of a steam boiler with steam superheater and re-heater, three-cylinder (casing) steam turbine with electric generator, condenser and feed water regeneration system with deaerator. During adaptation of chosen thermodynamic cycle to the binary cascade 
most of the model parameters were not changed. During data collection for different cycle configurations, the thermodynamic and flow parameters up to point 07 (at the LP turbine inlet) and from point 35 (before heat exchanger No. 4) (see thermodynamic scheme shown in Fig. 1) were always constant and same as for the reference model.

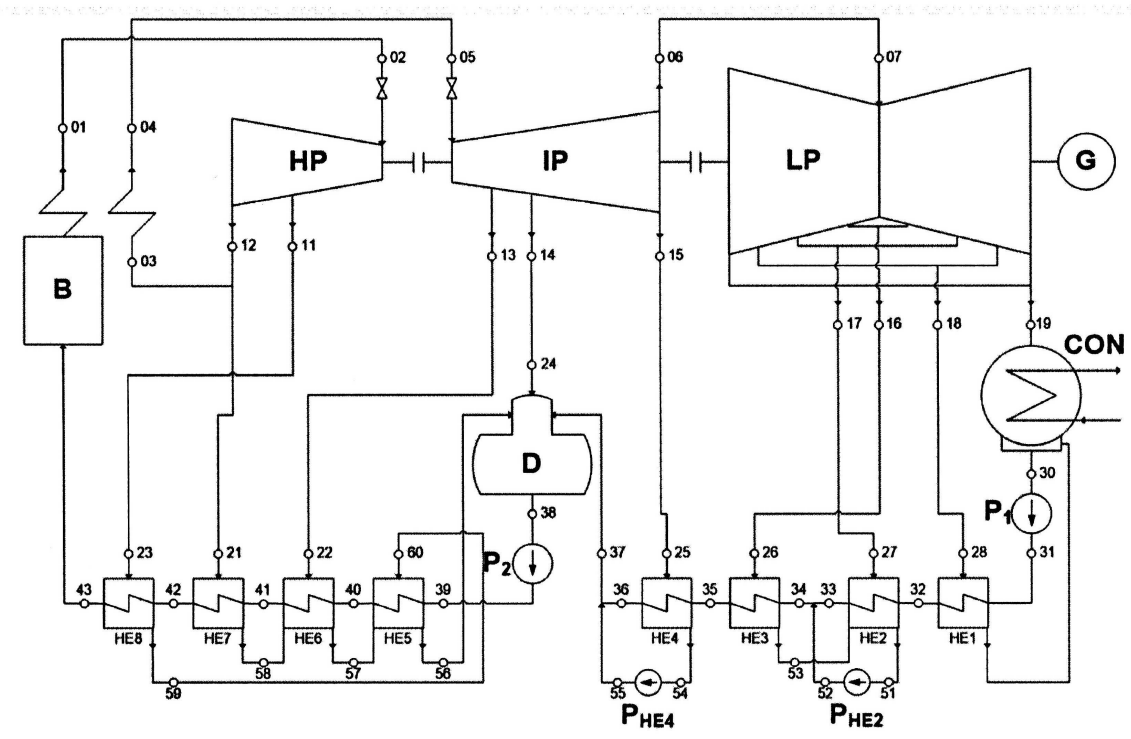

Figure 1: Thermodynamic scheme of the supercritical steam power plant - reference model, where: B - steam boiler with superheater, HP - high pressure steam turbine, IP - intermediate pressure steam turbine, LP - low pressure steam turbine, $\mathrm{P}$ - water pumps, CON - condenser, D - deaerator, G - electric generator, $\mathrm{HE}$ - regeneration heat exchangers.

In order to more clearly show the heat transfer and steam expansion phenomena occurring in the reference model devices, interpretation at the temperature - specific entropy diagram is shown in Fig. 2. The characteristic points of the thermodynamic cycle are labeled the same as in Fig. 1. Bold lines indicate the main thermodynamic cycle, thin lines indicate steam extractions and their condensation temperatures and dashed lines indicate water saturation line. The thermodynamic parameters of the reference model have been validated with the literature data $[4,7]$. The most significant difference between the reference model and literature data is steam turbines output power lower by $510 \mathrm{~kW}$, which gives $899490 \mathrm{~kW}$ for the reference model instead of $900000 \mathrm{~kW}$ for the real cycle. 


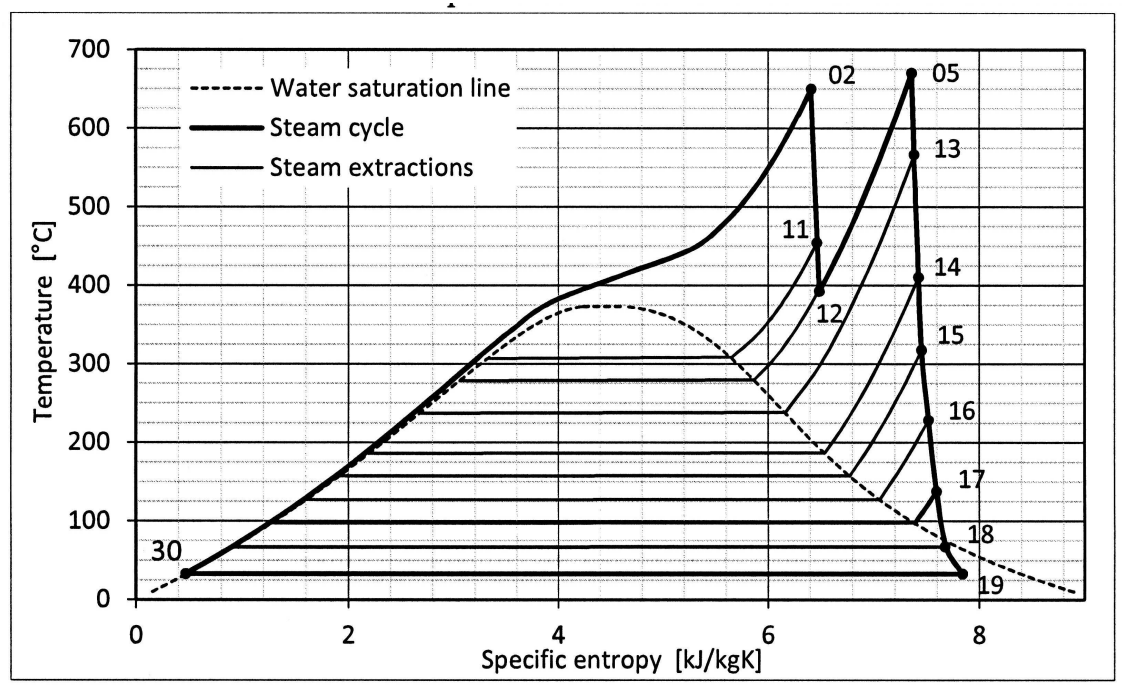

Figure 2: Characteristic thermodynamic points of the reference model represented in the Temperature - Specific entropy diagram interpretation.

Correct and convergent mathematical model constituted a basis for the whole analysis. The next step is to modify the reference model into the Szewalski cycle with and without the waste heat regeneration system and analyse changes of the exergy losses.

\subsection{The Szewalski cycle}

The Szewalski cycle has been modeled using a reference cycle as a basis. LP steam turbine has been replaced by smaller LP* steam turbine which provide shorter expansion of steam. It has been assumed that $\mathrm{HE}_{O R C}$ heat exchanger (Fig. 3), is at the same time a steam condenser on one hand and a generator of vapour of the low-boiling point fluid on the other hand. The level of condensate regeneration (HE) is constant, hence temperature feeding the boiler is constant and equal to $T_{43}=310^{\circ} \mathrm{C}$. At the same time the rate of heat to the boiler does not change, in order to produce live steam with parameters presented in [4].

In calculations of the Szewalski binary vapour cycle, the minimum temperature difference between the evaporating low boiling point fluid and condensing steam has been assumed at a level $\Delta T=5 \mathrm{~K}$. In case of the ORC condenser, there has been assumed temperature of the phase change 


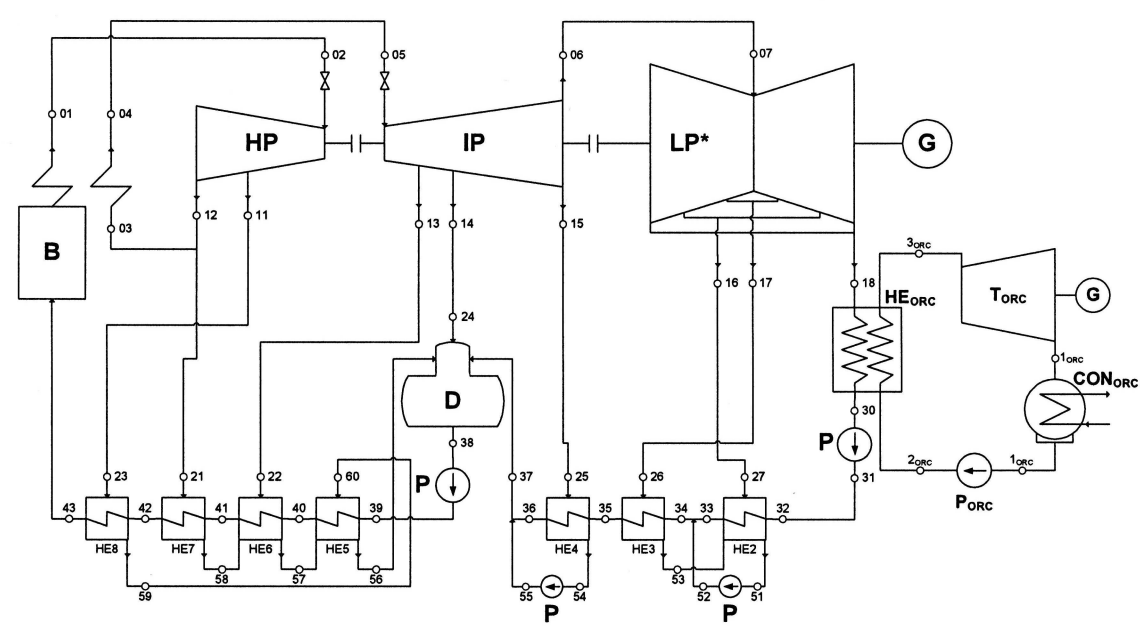

Figure 3: General scheme of the Szewalski binary vapour cycle, where additionally in comparison to Fig. 1: $\mathrm{T}_{O R C}$ - turbine of organic Rankine cycle, $\mathrm{P}_{O R C}-$ pump of organic Rankine cycle, $\mathrm{CON}_{O R C}$ - condenser of organic Rankine cycle, $\mathrm{HE}_{O R C}$ - heat exchanger, which is on one side the steam condenser and the generator of vapour of the low-boiling point fluid.

the same as in the reference cycle, that is $T_{\text {con }}=32.8^{\circ} \mathrm{C}$. Moreover, the efficiencies of the ORC system elements were all set as fallows: turbine $\left(\mathrm{T}_{O R C}\right)$ : internal $\eta_{i T}=0.90$, mechanical $\eta_{m T}=0.99$; pump $\left(\mathrm{P}_{O R C}\right)$ : internal $\eta_{i P}=0.85$, mechanical $\eta_{m P}=0.99$; generator $\eta_{g}=0.97$ and heat exchanger $\eta_{H E}=0.98$. It has been additionally assumed that condensate is not subcooled after condensation neither in the condenser of low-boiling point fluid $\left(\mathrm{CON}_{O R C}\right)$ nor in the ORC heat exchanger $\left(\mathrm{HE}_{O R C}\right)$ [4]. The calculations of the heat cycle had been done for the constant live steam parameters of $30.3 \mathrm{MPa} / 653^{\circ} \mathrm{C}$ (point 01 in Figs. 1 and 2). Characteristic points of the conventional steam cycle (01-60) and the ORC cycle (ORC1ORC4) have been presented in Fig. 3.

\subsection{The Szewalski binary vapour cycle with waste heat regeneration system}

The reason for improving the Szewalski binary vapour cycle was the work of Polko [29], who proposed a heat recovery system for a lignite fired boiler exhaust gases. Moreover, the system was proposed for the same supercritical steam power plant as is used as a reference cycle. The economizer (E in 
Fig. 4) made of plastic material is able to heat the mass flow-rate of water from about $50^{\circ} \mathrm{C}$ to $90^{\circ} \mathrm{C}$. Flux of recovered heat, according to Polko [29], is assumed as 200 MWt. Scheme of the Szewalski cycle for the 'cut-off' point at steam extraction No. 17 with additional waste heat recovery system, composed of water heat exchanger WHE, water pump $\mathrm{P}_{W}$ and the economiser E, is shown in Fig. 4.

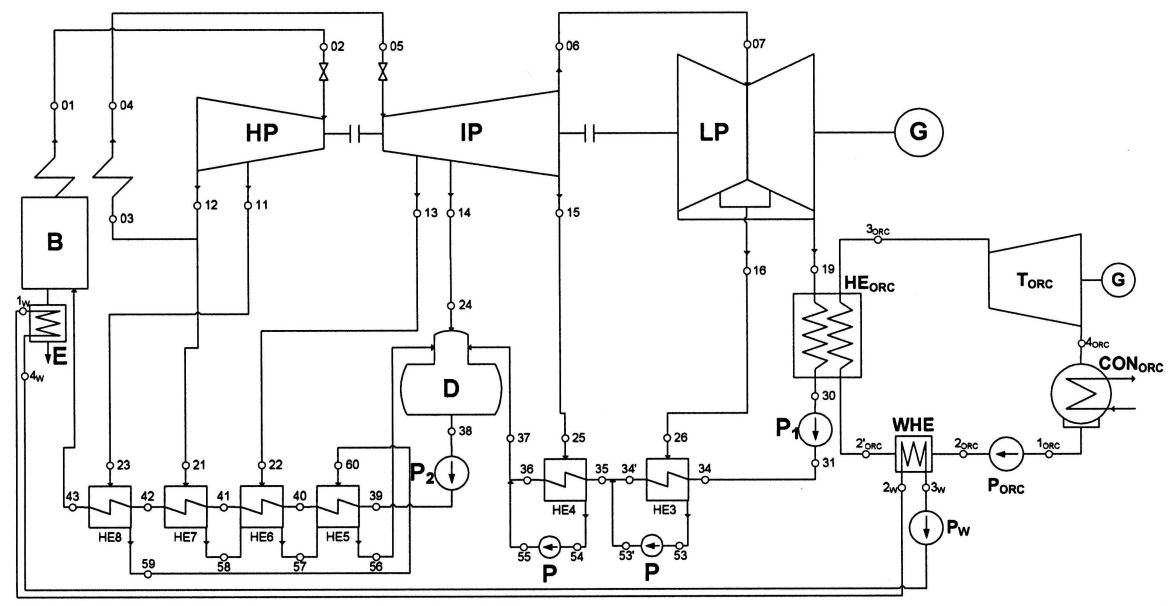

Figure 4: Scheme of the Szewalski binary vapour cycle with the waste heat recovery system, where compared to Fig. 3: WHE - waste heat exchanger with use water with temperature of $90^{\circ} \mathrm{C}, \mathrm{P}_{w}-$ pump of circulated water, $\mathrm{E}$ - economizer which heats water up to $90^{\circ} \mathrm{C}$ using exhaust gases.

In proposed configuration the heat exchanger No. 1 (HE1 according to the Fig. 1) has been removed and heat exchanger HE2 has been replaced by the $\mathrm{HE}_{O R C}$. Steam parameters at the outflow of the LP turbine in point 19 are equal to parameters in point 17 in the reference cycle. LP steam turbine is divided into a new, smaller LP* steam turbine and the ORC Turbine, ORC condenser $\left(\mathrm{CON}_{O R C}\right)$ overtook the steam condenser $(\mathrm{CON})$ role. ORC Pump is an additional device which has no counterpart in the reference cycle.

The ORC installation has been designed as a simplest, therefore also smallest and cheapest cycle, without vapour superheater and regeneration heat exchangers between the ORC condenser and the vapour generator $\left(\mathrm{HE}_{O R C}\right)$. Cycle has been tested using four low boiling points fluids: ethanol, ammonia, propane and isobutane. Fluids were chosen, using literature data $[3-5,30-33]$, as the most proper in this range of temperature. 
In calculations of the ORC, a temperature difference between the heated working fluid and the circulating water is a resulting temperature, however it has been assumed that it cannot be lower than $5 \mathrm{~K}$. For the optimal case, in which steam condensation temperature is $90^{\circ} \mathrm{C}$, it is equal to $5 \mathrm{~K}$. Temperature difference between the evaporating low-boiling point fluid and condensing steam is always equal to $5 \mathrm{~K}$. Additionally, it has been assumed that water temperature at the inlet to the WHE is $90^{\circ} \mathrm{C}$ and it is cooled down to $50{ }^{\circ} \mathrm{C}$ at the outlet. Moreover, the main parameters of the Szewalski binary vapour cycle with waste heat regeneration, such as temperature of condensing and subcooling in condenser or the live steam and feeding water parameters are the same as for the reference cycle. The temperature - specific entropy diagram of the cycles for the most efficient configuration is shown in Fig. 5.

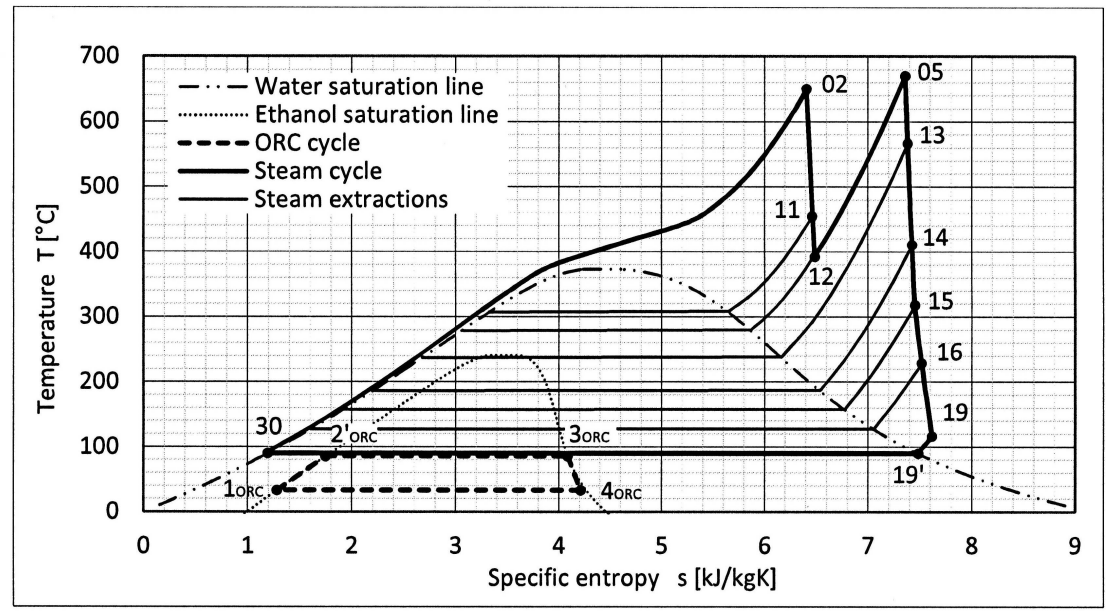

Figure 5: Characteristic thermodynamic points of the Szewalski cycle and the Szewalski cycle with the waste heat regeneration system in the temperature - specific entropy diagram interpretation.

The characteristic points of the thermodynamic cycle are labelled the same as in Fig. 4. Bold lines indicate the main thermodynamic cycle, thin line indicate steam extractions and their condensation temperatures, dashed lines indicate the ORC cycle. In the most efficient configuration a working fluid in the ORC cycle is ethanol and steam condensation temperature is equal to $90^{\circ} \mathrm{C}$, as is shown in Fig. 5 . 


\section{$3 \quad$ Exergy losses analysis}

To conduct a reliable analysis of a thermodynamic cycle, particularly a complex hierarchical cycle, exergy analysis in addition to thermodynamic analysis is recommended [34]. The exergy analysis yields a value of efficiency related to the 'available energy' that can be converted into work. The main feature of the exergy balance is usage of the thermodynamic temperature, which involves entropy generation. In this case, the ideal Carnot cycle always reaches $100 \%$ efficiency and it shows if the analyzed cycle is closer to, or more distant from the Carnot cycle efficiency [35]. Moreover, due to the analysis of the exergy losses in the cycle it is possible to undertake proper optimization steps in selected devices to improve technical processes.

To begin the exergy analysis, we describe the exergy flux, $\dot{B}$, according to [34] as a sum of a usable part of the internal and external fluxes of energy:

$$
\dot{B}=\dot{E}_{k}+\dot{E}_{p}+\dot{B}_{t}
$$

where $\dot{E}_{k}$ and $\dot{E}_{p}$ describe the potential and kinetic fluxes of energy, respectively, and $\dot{B}_{t}$ are thermal exergy fluxes consisting of two elements:

$$
\dot{B}_{t}=\Delta_{0} \dot{B}+\dot{B}_{c h} .
$$

The $\Delta_{0} \dot{B}$ element describes the flux of physical exergy, which includes pressure and thermal exergy flux differences between the substance thermodynamic state and ambient parameters. The $\dot{B}_{c h}$ parameter describes the chemical energy of the substance assuming ambient temperature and pressure.

Narrowing down our considerations to fluid-flow machinery with adiabatic insulation from the environment, we can assume that the maximal technical work of the machinery is equal to the thermal exergy decrease of the thermodynamic fluid, which can be written as

$$
-\Delta \dot{B}_{t}=\dot{I}_{1}-\dot{I}_{2}+\dot{Q}_{0}
$$

where $\dot{I}_{1}$ and $\dot{I}_{2}$ are the inlet and outlet enthalpy flux of the process, respectively, and $\dot{Q}_{0}$ is the amount of useless heat exchanged with the environment.

According to the entropy definition from the second law of thermodynamics, the thermal exergy decrease can be described as

$$
-\Delta \dot{B}_{t}=\dot{I}_{1}-\dot{I}_{2}-T_{0}\left(\dot{S}_{1}-\dot{S}_{2}\right),
$$


where $T_{0}$ is the ambient temperature and $\dot{S}_{1}, \dot{S}_{2}$ are the inlet and outlet entropy fluxes, respectively.

However, if the chemical energy conversion of fuel in combustion chamber, boiler or fuel cell is taken into consideration, the flux of physical energy $\Delta \dot{B}_{t}$ must be applied to Eq. (4) so Eq. (2) becomes

$$
\dot{B}_{t}=\Delta_{0} \dot{I}-T_{0} \Delta_{0} \dot{S}+\dot{B}_{c h} .
$$

The procedure for evaluating the chemical exergy depends on the type of the reaction and the substrates. A complete procedure for a combustion process is presented in [34].

To close the exergy balance of the thermodynamic process, it is necessary to define the exergy losses. To illustrate the balance equations, a model of the thermal engine is presented in Fig. 6.

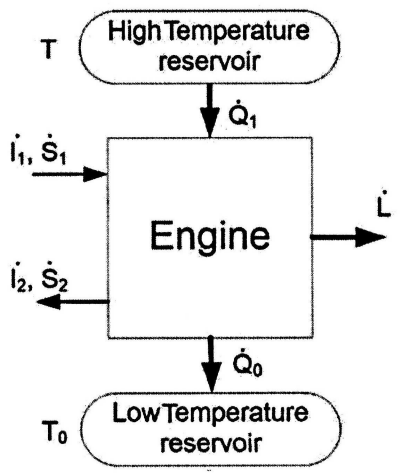

Figure 6: Model of a thermal engine.

The proposed engine, a binary vapor cycle in this case, uses a flux of thermal energy, $\dot{Q}_{1}$, yields a flux of mechanical work, $\dot{L}$, and dumps a flux of worthless thermal energy, $\dot{Q}_{0}$. Additionally, coolant with an inflow flux enthalpy $\dot{I}_{1}$ and entropy $\dot{S}_{1}$ is heated to parameters $\dot{I}_{2}$ and $\dot{S}_{2}$.

In general, the flux of exergy losses in machinery can be defined using the energy balance equation of real and ideal processes, respectively:

$$
\begin{gathered}
\dot{L}=\dot{Q}_{1}+\dot{I}_{1}-\dot{I}_{2}-\dot{Q}_{0}, \\
\dot{L}_{\text {max }}=\dot{Q}_{1}+\dot{I}_{1}-\dot{I}_{2}-\dot{Q}_{0, s} .
\end{gathered}
$$


Using real and ideal processes and the flux of work definition based on Eqs. (6) and (7), the flux of exergy loss is defined as the difference between ideal process and real process fluxes of work, or fluxes of waste energy from real and ideal processes:

$$
\delta \dot{B}=\dot{L}_{\text {max }}-\dot{L}=\dot{Q}_{0}-\dot{Q}_{0, s} .
$$

According to the second law of thermodynamics, the sum of the entropy fluxes in a system is more than 0 , and the flux of entropy generation during a process can be described as

$$
\dot{\Pi}=-\frac{\dot{Q}_{1}}{T}+\dot{S}_{2}-\dot{S}_{1}+\frac{\dot{Q}_{0}}{T_{0}} .
$$

In the ideal process, the sum of entropy fluxes equals 0 :

$$
0=-\frac{\dot{Q}_{1}}{T}+\dot{S}_{2}-\dot{S}_{1}+\frac{\dot{Q}_{0, s}}{T_{0}} .
$$

By subtracting Eq.(9) from Eq. (10), we obtain

$$
\dot{\Pi} T_{0}=\dot{Q}_{0}-\dot{Q}_{0, s} \text {. }
$$

Furthermore, by inserting Eq. (11) into Eq. (8), we can define the flux of exergy losses as the Gouy-Stodola law $[24,34]$

$$
\delta \dot{B}=\dot{\Pi} T_{0} .
$$

To analyze the share of each machine in the cycle relative exergy losses, it is useful to employ the proportion of exergy losses in the cycle driving exergy as a mass flow rate of the fuel and unit fuel exergy [24]

$$
\xi=\frac{\delta \dot{B}}{\dot{m}_{\text {Fuel }} b_{\text {Fuel }}},
$$

where $\dot{m}_{F u e l}$ is a fuel mass flow rate, $b_{F u e l}$ is the specific fuel exergy and $\delta \dot{B}$ is the flux of exergy losses.

For example, the relative exergy losses in a model of a one-cylinder steam turbine and electric generator set $\xi_{T-G}$ are given by

$$
\xi_{T-G}=\frac{\dot{m}_{s t}\left[\left(1-\eta_{m, T} \eta_{e l, G}\right)\left(i_{s t}-i_{c}\right)-T_{0}\left(s_{s t}-s_{c}\right)\right]}{\dot{m}_{\text {Fuel }} b_{F u e l}}
$$


and for water pump and electric motor set

$$
\xi_{P}=\frac{\left(1-\eta_{e l, P} \eta_{m, P}\right) N_{e l, P}}{\dot{m}_{\text {Fuel }} b_{F u e l}},
$$

where: $\dot{m}_{s t}$ - steam mass flow rate, $\eta_{m}$ - mechanical efficiency, $\eta_{e l}-$ mechanical and electrical efficiency of electric generators/motors, indexes: $T$, $G, P$ corresponds respectively to steam turbine, electric generator and water pump.

The related exergy losses in steam condenser can be described as a difference between exergy flux of the turbine outlet steam and the condensate:

$$
\xi_{C}=\frac{\dot{m}_{s t}\left(b_{s t}-b_{c}\right)}{\dot{m}_{\text {Fuel }} b_{\text {Fuel }}}=\frac{\dot{m}_{s t} x r}{\dot{m}_{\text {Fuel }} b_{\text {Fuel }}} \frac{T_{s t}-T_{0}}{T_{s t}},
$$

where: $b_{s t, 2}$ and $b_{c}$ - outlet steam and condensate specific exergy, $x$ - dryness fraction of turbine outlet steam, $r$ - specific evaporation heat, $T_{s t, 2}-$ outlet steam absolute temperature.

The most general and the simplest formula for the exergetic efficiency refers to the ratio of the driving exergy, $B_{D, s}$, of a reversible ideal thermodynamic process to the driving exergy of a real process, $B_{D}[24,34]$ :

$$
\eta_{b}=\frac{B_{D, s}}{B_{D}} .
$$

From Eq. (17), one can see that the ideal Carnot cycle attains an exergetic efficiency of $100 \%$, which is why, in general, the exergetic efficiency of thermodynamic cycles can be viewed as a fraction of the Carnot ideal cycle. A more accurate equation depends on the kind of physical process or, in case of the thermodynamic cycle, on the complexity of the cycle. For instance, the exergy efficiency of a pump (18) and the gross exergy efficiency of a steam boiler (19) can be given as

$$
\begin{gathered}
\eta_{b, P}=\eta_{m}\left(\frac{T_{0}}{T_{\text {mean }}} \eta_{\text {int }}+\frac{T_{\text {mean }}-T_{0}}{T_{\text {mean }}}\right), \\
\eta_{b, B}=\frac{\dot{m}_{\text {st }}\left(b_{\text {st }}-b_{w}\right)}{\dot{m}_{\text {Fuel }} b_{\text {Fuel }}}=\frac{\dot{m}_{\text {st }}\left[i_{\text {st }}-i_{w}-T_{0}\left(s_{s t}-s_{w}\right)\right]}{\dot{m}_{\text {Fuel }} b_{\text {Fuel }}},
\end{gathered}
$$

where $\eta_{m}$ is the pump mechanical efficiency, $\eta_{i n t}$ is the pump internal efficiency, and $T_{\text {mean }}$ is the pumped media mean absolute temperature. If we would replace the expression $\dot{m}_{F u e l} b_{F u e l}$ in Eq. (19) with the mass stream 
and exergy change of heating media $\dot{m}_{h m}\left(b_{h m}-b_{h m}\right)$ then it would describe a heat exchanger.

Exergetic efficiency of more complex model of real machinery or thermodynamic system can be easy estimated by the balance of losses

$$
\eta_{b}=1-\sum_{i=1}^{n} \xi_{i}
$$

where index $i$ denotes the number of machines.

For a simple model of the Clausius-Rankine cycle, the exergy balance is given as follows:

$$
\eta_{b, C-R}=1-\xi_{B}-\xi_{T-G}-\xi_{C}=1-\left(1-\eta_{b, B}\right)-\xi_{T-G}-\xi_{C} .
$$

In the present case, the ORC installation is added to supercritical steam cycle which is already optimized. That is why, to skip time-consuming detailed analysis of whole cycle, we have decided to perform the exergy losses analysis only for the ORC installation and modified devices in the reference cycle. Next we have compared the results with those ones for the same machinery from the reference cycle to estimate the changes in exergy losses. Steam cycle parameters were changed between LP turbine second steam extraction, point 17 due to the schemes in Figs. 1, 3 and 4, and regeneration heat exchanger HE2, plus steam boiler which in the proposed cycle is considered as steam boiler from the reference cycle with additional heat exchanger - the economizer (E in Fig. 4).

For comparison, the electric net power Eq. (22) and electric net efficiency Eq. (23) are defined as

$$
\begin{gathered}
N_{e l, n e t}=N_{e l}-\sum_{i=1}^{n} N_{P}{ }_{i}, \\
\eta_{\text {el,net }}=\frac{N_{\text {el,net }}}{\dot{Q}_{\text {ch,Fuel }}},
\end{gathered}
$$

where: $N_{e l, n e t}$ - cycle electric net power, $N_{e l}$ - electric generator output power (steam and ORC cycle), $N_{P}$ - pump power demand, $\eta_{e l, n e t}$ - electric net efficiency, $\dot{Q}_{c h, F u e l}$ - stream of fuel chemical energy, index $i=1,2, \ldots, n$ - number of pump. 


\section{Results}

The modernized Szewalski cycle was modeled for variable conditions, in meaning of four low-boiling point fluids and different temperatures of the ORC live vapour temperatures and pressures. The diagram of cycle electric net power, $N_{e l, n e t}$, and cycle electric net efficiency, $\eta_{e l, n e t}$, vs. ORC turbine inlet temperature, $T_{3 O R C}$, is presented in Fig. 7.

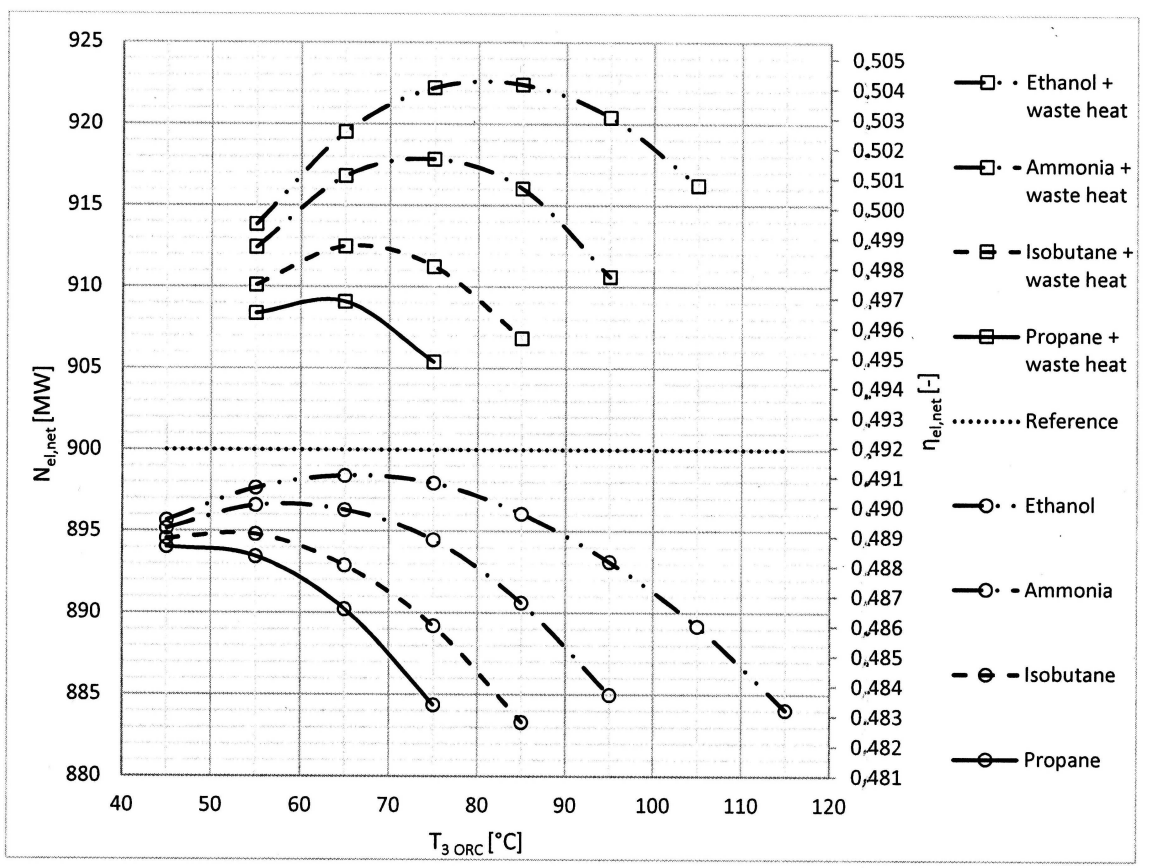

Figure 7: Power and efficiency characteristics of the Szewalski binary vapour cycle cooperating with a waste heat recovery system for four tested low-boiling point fluids. Electric net power, $N_{e l}$ and the electric net efficiency, $\eta_{e l, n e t}$, vs. ORC turbine inlet temperature $T_{3 O R C}$ and type of the low-boiling point fluid [5].

The dotted line shows reference cycle electric net power and electric net efficiency, curves of selected fluids shows those parameters due to difference temperatures of working fluid at the ORC turbine inlet (in point 3 ORC due to Figs. 3-5). Temperature of steam condensation is higher by $5 \mathrm{~K}$, so it is in range of $60-110^{\circ} \mathrm{C}$.

Preliminary calculations have shown than the highest electric net power and efficiency is achieved for ethanol at vapour temperature at the inlet to 
the ORC turbine in range of $80-85^{\circ} \mathrm{C}$. Second fluid, due to achieved efficiency, is ammonia under temperature of $70-75^{\circ} \mathrm{C}$. Isobutane and propane have achieved the lowest efficiency. Isobutane vapour at the outlet from the turbine was a superheated vapour, however the temperature was about $10 \mathrm{~K}$ above the condensation temperature so there was no economic reasons and technical possibilities to effectively use the regeneration heat exchanger.

Calculation results for the Szewalski cycle with waste heat regeneration system were compared with the Szewalski cycle and the reference model data. Table 1 presents the chosen main devices parameters as electric generator power, pumps demand, electric output power, the cycles net efficiency and main thermodynamic parameters of working media.

Table 1: Main parameters of the Szewalski cycle with waste heat regeneration system compared to the Szewalski cycle and the reference steam cycle.

\begin{tabular}{|l|l|l|l|l|l|}
\hline \multicolumn{1}{|c|}{ Parameter } & Symbol & Unit & $\begin{array}{l}\text { Reference } \\
\text { cycle }\end{array}$ & $\begin{array}{l}\text { Szewalski } \\
\text { cycle }\end{array}$ & $\begin{array}{l}\text { Szewalski } \\
\text { cycle+waste } \\
\text { heat }\end{array}$ \\
\hline \hline Electric generator power & $N_{e l}$ & $\mathrm{~kW}$ & 899490 & 898479 & 922645 \\
\hline Pumps demand & $\sum N_{P}$ & $\mathrm{~kW}$ & 28874 & 28947 & 30830 \\
\hline Electric output power & $N_{\text {el,net }}$ & $\mathrm{kW}$ & 871126 & 869532 & 893307 \\
\hline $\begin{array}{l}\text { Cycle electric net effi- } \\
\text { ciency }\end{array}$ & $\eta_{\text {el,net }}$ & - & 0.4758 & 0.4746 & 0.4876 \\
\hline - Mass stream of water & $\dot{m}_{\text {Water }}$ & $\mathrm{kg} / \mathrm{s}$ & \multicolumn{3}{|c|}{619} \\
\hline Mass stream of ethanol & $\dot{m}_{E \text { thanol }}$ & $\mathrm{kg} / \mathrm{s}$ & - & 942 & 1175 \\
\hline $\begin{array}{l}\text { Live steam/vapour tem- } \\
\text { perature }\end{array}$ & $t_{02} / t_{3 O R C}$ & ${ }^{\circ} \mathrm{C}$ & $650 /-$ & $650 / 65$ & $650 / 85$ \\
\hline $\begin{array}{l}\text { Live steam/vapour pres- } \\
\text { sure }\end{array}$ & $p_{02} / p_{3 O R C}$ & $\mathrm{MPa}$ & $30 /-$ & $300 / 0.61$ & $300 / 1.35$ \\
\hline $\begin{array}{l}\text { Steam/vapour condensa- } \\
\text { tion temperature }\end{array}$ & $t_{30} / t_{1 O R C}$ & ${ }^{\circ} \mathrm{C}$ & $32 /-$ & $70 / 32$ & $90 / 32$ \\
\hline $\begin{array}{l}\text { Steam/vapour condensa- } \\
\text { tion pressure }\end{array}$ & $p_{30} / p_{1 O R C}$ & $\mathrm{MPa}$ & 0.005 & $0.70 / 0.13$ & $0.70 / 0.13$ \\
\hline
\end{tabular}

Comparison of the calculation results has shown that in the Szewalski cycle with waste heat regeneration system power of electric generator and pumps demand has increased by the most, respectively by $23 \mathrm{MW}$ and almost $2 \mathrm{MW}$. High increase in pumps demand is caused by addition of two pumps, which are required in the cycle comparing to the reference steam cycle. Power demand of the additional ORC pump for ethanol is relatively 
low, in order to others tested fluids, because of low pressure ratio between saturation and condensation temperatures.

The reference model has been changed by replacing of the LP steam turbine with a new smaller LP steam turbine and additional ORC turbine. LP turbine efficiency was divided into parts: 0.80 for the last stage and 0.85 for others stages. Because dimension of the ORC turbine is significantly reduced, in comparison to the reference LP turbine. Moreover, outflow to inflow dimension rate is also smaller, dryness fraction of expanded vapour is higher than for a steam, respectively 0.95 to 0.93 , so the ORC turbine can be designed with a higher internal efficiency. Thereby value of 0.90 for ORC turbine internal efficiency has been assumed [4]. The results of the simplified exergy analyses of the reference cycle machinery and their equivalent machinery in the Szewalski cycle are presented in Tab. 2.

Exergy analysis has shown that modification of the reference cycle into the Szewalski cycle, through increase of output power, introduces some additional exergy losses. Waste heat regeneration system improves boiler exergetic efficiency, thereby decreases its corresponding exergy losses. However, recovered thermal energy has low exergy and cycle modification, though increase of exergetic efficiency of most cycle devices increases also their power. That increase related exergy losses, particularly in devices supplied by steam, exhibit higher exergy than waste heat. The most significant exergy losses occur in the $\mathrm{HE}_{O R C}$, because though better temperature distribution and higher exergetic efficiency, its power increases over 23 times and is supplied with superheated steam. The only device that efficiency has slightly decreased is the HE2*. Decrease of the efficiency is caused by the worse temperature distribution in the heat exchanger.

For the highest thermodynamic efficiency, for proposed cycle configuration, condensation temperature is equal to hot supply of the preheating heat exchanger WHE, which is $90^{\circ} \mathrm{C}$. This provides optimal conditions of heat exchange, however in this case outlet steam from LP turbine is a superheated steam. It causes some exergy losses, because the organic fluid supplies the ORC turbine as a saturated vapour. To avoid these losses the ORC vapour should be also superheated to hold the temperature difference between steam and low-boiling point fluid. However, due to proposed investigation of few working fluids it was intend to provide the same thermodynamic conditions for each of them.

Exergy analysis shows that replacement of one LP steam turbine by smaller $\mathrm{LP}^{*}$ steam turbine and ORC turbine has only a slight increase on 
Table 2: Impact of the reference cycle to the Szewalski cycle and the Szewalski cycle with waste heat regeneration system modernization onto exergy balance for the cycle devices, due to nomenclature from Figs. 2,3 and 5.

\begin{tabular}{|c|c|c|c|c|c|c|}
\hline \multicolumn{3}{|c|}{ Devices } & \multirow[b]{2}{*}{$\begin{array}{l}\text { Type } \\
\text { value }\end{array}$} & \multicolumn{3}{|c|}{ Exergy analysis } \\
\hline $\begin{array}{c}\text { Reference } \\
\text { cycle }\end{array}$ & $\begin{array}{c}\text { Szewalski } \\
\text { cycle }\end{array}$ & $\begin{array}{l}\text { Szewalski } \\
\text { cycle }\end{array}$ & & $\begin{array}{c}\text { Reference } \\
\text { cycle }\end{array}$ & $\begin{array}{c}\text { Szewalski } \\
\text { cycle }\end{array}$ & $\begin{array}{c}\text { Szewalski } \\
\text { cycle+waste } \\
\text { heat }\end{array}$ \\
\hline \multirow[t]{3}{*}{$\mathrm{LP}$} & $\mathrm{LP}^{*}+T_{O R C}$ & $\mathrm{LP}^{*}+T_{O R C}$ & $N[\mathrm{~kW}]$ & 282613 & 280684 & 304860 \\
\hline & & & $\eta_{b}$ & 0.81 & 0.85 & 0.85 \\
\hline & & & $\xi$ & 0.0254 & 0.0199 & 0.0216 \\
\hline \multirow[t]{2}{*}{$\mathrm{CON}$} & $\mathrm{CON}_{O R C}$ & $\mathrm{CON}_{O R C}$ & $N$ [MW] & 835 & 860 & 1015 \\
\hline & & & $\xi$ & 0.0188 & 0.0243 & 0.0286 \\
\hline \multirow[t]{3}{*}{ HE1 } & $\mathrm{HE}_{O R C}$ & - & $N$ [MW] & 51 & 913 & - \\
\hline & & & $\eta_{b}$ & 0.71 & 0.97 & - \\
\hline & & & $\xi$ & 0.0070 & 0.0130 & - \\
\hline \multirow[t]{3}{*}{ HE2 } & $\mathrm{HE} 2^{*}$ & $\mathrm{HE}_{O R C}$ & $N$ [MW] & 50 & 40 & 1167 \\
\hline & & & $\eta_{b}$ & 0.83 & 0.86 & 0.98 \\
\hline & & & $\xi$ & 0.0040 & 0.0026 & 0.0110 \\
\hline \multirow[t]{3}{*}{$\mathrm{B}$} & $\mathrm{B}$ & $\mathrm{B}+\mathrm{E}$ & $N$ [MW] & 1727 & 1727 & 1927 \\
\hline & & & $\eta_{b}$ & 0.48 & 0.48 & 0.51 \\
\hline & & & $\xi$ & 0.5180 & 0.5180 & 0.4912 \\
\hline \multirow[t]{3}{*}{-} & - & WHE & $N$ [MW] & - & - & 200 \\
\hline & & & $\eta_{b}$ & - & - & 0.89 \\
\hline & & & $\xi$ & - & - & 0.0104 \\
\hline \multirow[t]{3}{*}{$P_{1}$} & $P_{1}{ }^{*}$ & $P_{1}^{*}$ & $N[\mathrm{~kW}]$ & 1222 & 1228 & 1261 \\
\hline & & & $\eta_{b}$ & 0.87 & 0.90 & 0.90 \\
\hline & & & $\xi$ & 0.0001 & 0.0001 & 0.0001 \\
\hline \multirow[t]{3}{*}{-} & $P_{O R C}$ & $P_{O R C}$ & $N[\mathrm{~kW}]$ & - & 73 & 232 \\
\hline & & & $\eta_{b}$ & - & 0.87 & 0.87 \\
\hline & & & $\xi$ & - & $\approx 0$ & $\approx 0$ \\
\hline \multirow[t]{3}{*}{-} & - & $P_{W}$ & $N[\mathrm{~kW}]$ & - & - & 1685 \\
\hline & & & $\eta_{b}$ & - & - & 0.89 \\
\hline & & & $\xi$ & - & - & 0.0001 \\
\hline
\end{tabular}

its related exergy losses. That is because internal efficiency and enthalpy drop are nearly the same in both cycles, moreover 'external' thermodynamic parameters for $\mathrm{LP}$ and $\mathrm{LP}^{*}+T_{O R C}$ are constant. Increase of exergy losses is caused because of power increase. Slight increase of related exergy losses in the ORC condenser $\left(\mathrm{CON}_{O R C}\right)$, though the same thermodynamic 
parameters in both cycles, is caused by removal of steam extractions and regeneration steam exchanger. That leads to increase of steam mass flow rate injected into the condenser. Next modification is about replacing of regeneration heat exchanger HE1 or HE2, depending on configuration, by the ORC vapour generator $\left(\mathrm{HE}_{O R C}\right)$. In both cycles, for presented thermodynamic configuration, those devices have the most significant influence on the cycle exergy losses. Devices which are added to the Szewalski cycle and which have no counterpart in the reference model are the water pump and ORC pump. Though their high internal and exergy efficiency they can have significant impact on the cycle net electric output power and net efficiency. In presented configuration of thermodynamic parameters this influence is quite low, however increase of pressure ratio in the ORC cycle increases the role of pump in the balance. This situation occurs when higher thermodynamic parameters of ORC cycle are set. Then to provide proper temperature of working fluid evaporation, pressure in the heat exchanger needs to be higher. Different pressure ratio in the ORC installation also occurs for different working fluids. For instance, due to Fig. 7, investigated model for each low-boiling point fluid, in their optimal point, generates almost the same amount of electricity. That is because exergy losses in each device are minimalized and stay almost the same. However, electric net power is different for each media. This is caused by different pressure ratio in the cycle for each low-boiling point fluid, therefore also different pump power demand.

\section{Conclusion}

Performed analysis has revealed that the Szewalski binary vapour cycle, has a great potential in the field of reducing the size of power units [1-3] and increasing the efficiency of waste heat utilization in power plants, which can be used particularly in design of generating units of great output power and, what is desirable, for many technical and economic reasons. Unfortunately, binary cycle in contrast to single steam cycle, brings some additional energy losses, especially during heat exchange between the cycles.

For presented calculations, ethanol was chosen as a working, low-boiling point, fluid because of few reasons. Mainly it provides the highest increase of the power unit output power. To achieve higher efficiency of the cycle, working fluid should be superheated before turbine inlet. That would decrease exergy losses in the $\mathrm{HE}_{O R C}$. 
Presented thermodynamic configuration of the cycle is a result of optimization process. Thanks to that heat exchanger, which plays a key role in the hierarchical cycles, high entropy generation, therefore significant exergy losses are not developed. Exergy analysis is an important tool in optimization of complex thermodynamic processes, because energy balance does not include entropy generation, and therefore energy quality degradation. For technical and economic reasons quality of energy is closely related with initial and maintenance costs. For those reasons temperature and entropy, as a potential of energy conversion phenomena, coupled in the exergy balance cannot be omitted in the process of design and optimization, particularly when temperatures of hot and cold reservoirs are set, e.g., in binary vapour cycles, gas-steam cycles or in low-temperature waste heat recovery systems. For heat transfer processes like combustion, mixing or heat exchanging exergy analysis is particularly recommended because it is a measure of process irreversibility.

Throughout the exergy analysis, little difference between the reference cycle and the Szewalski cycle can be observed. From the values presented in Table 2, it can be seen that the related exergy losses have increased in case of the Szewalski cycle by about 0.001, and in the case of the Szewalski cycle with waste heat regeneration system decrease of about 0.01 .

Furthermore, the thermodynamic analysis (first law) revealed that the reference cycle with efficiency of 0.4785 is more efficient than the Szewalski cycle by 0.0012 , but energy efficiency of the Szewalski cycle with waste heat regeneration system is bigger by 0.0118 .

Received 9 November 2015

\section{References}

[1] Szewalski R.: The binary vapour turbine set of great output, its concept and some basic engineering problems. Transactions IFFM 42-44(1969), 119-140.

[2] Szewalski R.: Actual problems of development of energetical technology. Enhancement of unit work and efficiency turbine and power unit. Ossolineum, Wrocław 1978 (in Polish).

[3] Kowalczyk T., ZióŁkowski P., Badur J.: Exergy losses in the Szewalski binary vapour cycle Entropy 17(2015), 10, 7242-7265.

[4] ZióŁkowski P., Hernet J., Badur J.: Revalorization of the Szewalski binary vapour cycle. Arch. Thermodyn. 35(2014), 3, 225-249. 
[5] ZióŁkowski P., Kowalczyk T., Hernet J., Kornet S.: The thermodynamic analysis of the Szewalski hierarchic vapour cycle cooperating with a system of waste heat recovery. Transactions IFFM after recession.

[6] ZióŁkowski P., Mikielewicz D.: Thermodynamic analysis of the supercritical 900 MWe power unit, co-operating with an ORC cycle. Arch. Energ. 42(2012), 165-174 (in Polish).

[7] ZıóŁkowski P., Mikielewicz D., Mikielewicz J.: Increase of power and efficiency of the $900 \mathrm{MW}$ supercritical power plant through incorporation of the ORC. Arch. Thermodyn. 34(2013), 4, 51-71.

[8] Mikielewicz D., Bartela Ł., ZióŁkowski P., Wajs J., Mikielewicz J.: Operation of the $900 \mathrm{MW}$ power plant with the ORC supplied from three heat sources. Current Power Engineering problems Vol. II, (K. Wójs, P. Szulc, Eds.), Publishers Wrocław University, 2014, 263-277.

[9] Mikielewicz D., ZióŁkowski P., Wajs J., Mikielewicz J.: Combined operations of $900 \mathrm{MW}$ power plant with the ORC through the bleed steam extraction point and $\mathrm{CO}_{2}$ recovery system. In: Proc. Heat Transfer and Renewable Sources of Energy 2014, ZUT, Szczecin 2014, 380-386.

[10] Łukowicz H., Kochaniewicz A.: Analysis of the use of waste heat obtained from coal-fired units in organic Rankine cycles and for brown coal drying. Energy 45(2012), 203-212.

[11] BARTNIK R.: Thermodynamic fundamentals for production of electric power in hierarchical $j$-cycle system. Transactions IFFM 126(2014), 141-151.

[12] Lazzaretto A.: Fuel and product definitions in cost accounting evaluations: Is it a solved problem? In: Proc. 12th Joint Eur. Thermodyn. Conf., Brescia, 2013 JETC 2013 (M. Pilotelli, G.P. Beretta, Eds.), 244-250.

[13] Rosen M.A., Bulucea C.A.: Using exergy to understand and improve the efficiency of electrical power technologies. Entropy 11(2009), 820-835, DOI:10.3390/e11040820.

[14] Gaggioli R., Reini M.: Panel I: Connecting 2nd law analysis with economics, ecology and energy policy. Entropy 16(2014), 3903-3938, DOI:10.3390/e16073903.

[15] Cenuşă V.E., Badea A., Feidt M., Benelmir R.: Exergetic optimization of the heat recovery steam generators by imposing the total heat transfer area. Int. J. Thermodyn. 7(2004), 3, 149-156.

[16] Feidt M.: Two examples of exergy optimization regarding the 'Thermo-Frigopump' and combined heat and power systems. Entropy 15(2013), 544-558.

[17] Feidt M., Costea M.: Energy and exergy analysis and optimization of combined heat and power systems. Energies 5(2012), 3701-3722.

[18] Zhai H., Dai Y.J., Wu J.Y., WANG R.Z.: Energy and exergy analyses on a novel hybrid solar heating, cooling and power generation system for remote areas. Appl. Energy 86(2009), 1395-1404.

[19] Dudar A., Butrymowicz D., Śmierciew K., Karwacki J.: Exergy analysis of operation of two-phase ejector in compression refrigeration systems. Arch. Thermodyn. 34(2013), 4, 107-122. 
[20] Barelli L., Bidini G., Gallorini F., Ottaviano A.: An energetic-exergetic comparison between PEMFC and SOFC-based micro-CHP systems. Int. J. Hydrogen. Energ. 36(2011), 3206-3214.

[21] Bingöl E., Ilkiş B., Eralp C.: Exergy based performance analysis of high efficiency poly-generation systems for sustainable building applications. Energ. Build. 43(2011), 3074-3081.

[22] Nieminen J., Dincer I.: Comparative exergy analyses of gasoline and hydrogen fuelled ICEs. Int. J. Hydrogen. Energ. 35(2010), 5124-5132.

[23] Abusoglu A., Kanoglu M.: Exergoeconomic analysis and optimization of combined heat and power production: a review. Renew. Sustain. Energ. Rev. 13(2009), 2295-2308.

[24] Szargut J.: Exergy method: technical and ecological applications.: WIT Press, Southampton 2005.

[25] Szargut J.T., ZięBiK A., Stanek W.: Depletion of the non-renewable natural exergy resources as a measure of the ecological cost. Energ. Convers. Manage. 43(2002), 1149-1163.

[26] ZiĘBiK A., GŁadysz P.: Thermoecological analysis of an oxy-fuel combustion power plant integrated with a CO2 processing unit. Energy 88(2015), 37-45.

[27] ZIĘBIK A., GŁADYsz P.: Analysis of the cumulative exergy consumption of an integrated oxy-fuel combustion power plant. Arch. Thermodyn. 34(2013), 3, 105122.

[28] Szargut J.T., Stanek W.: Thermo-ecological optimization of a solar collector. Energy 32(2007), 584-590.

[29] Polko K.: Modeling of waste heat recovery from exhaust flue gases. PhD thesis, Wrocław University of Technology, Wrocław 2012 (in Polish).

[30] BAO J., ZHAO L.: A review of working fluid and expander selections for organic Rankine cycle. Renew. Sust. Energ. Rev. 24(2013) 325-342.

[31] Horbaj P., Braunmiller G., Taus P.: On a environmentally friendly supply of energy . Transactions IFFM 124(2014) 221-230.

[32] SRinivas T., RedDy: Study on power plants arrangements for integration. Energ. Convers. Manage. 85(2014) 7-12.

[33] Vélez F., Segovia J.J., Martín M.C., Antolín G., Chejne F., Quijano A.: A technical, economical and market review of organic Rankine cycles for the conversion of low-grade heat for power generation. Renew. Sust. Energ. Rev. 16(2012), 6, 4175-89.

[34] Szargut J., Petela R.: Exergy. WNT, Warsaw 1965. (in Polish)

[35] Feidt M., Blaise M.: A new three objectives criterion to optimize thermomechanical engines model. In: Proc. 1st Int. e-Conf. on Energies, 14-31 March 2014. Available online http://sciforum.net/conference/ece-1(accessed on 10.09.2015). 